\title{
High Concentrations of the Antibiotic Spiramycin in Wastewater Lead to High Abundance of Ammonia-Oxidizing Archaea in Nitrifying Populations
}

Yu Zhang, ${ }^{* \dagger}$ Zhe Tian, $^{\dagger}$ Miaomiao Liu, ${ }^{\dagger}$ Zhou Jason Shi, ${ }^{\ddagger}$ Lauren Hale, ${ }^{\ddagger}$ Jizhong Zhou, ${ }^{\ddagger},, \|$ and Min Yang*,

\author{
${ }^{\dagger}$ State Key Laboratory of Environmental Aquatic Chemistry, Research Center for Eco-Environmental Sciences, Chinese Academy of \\ Sciences, P.O. Box 2871, Beijing 100085, China \\ ${ }^{\ddagger}$ Institute for Environmental Genomics, and Department of Microbiology and Plant Biology, University of Oklahoma, Norman, \\ Oklahoma 73019, United States \\ ${ }^{\S}$ Earth Sciences Division, Lawrence Berkeley National Laboratory, Berkeley, California 94720, United States \\ "State Key Joint Laboratory of Environment Simulation and Pollution Control, School of Environment, Tsinghua University, Beijing \\ 100084, China
}

\section{Supporting Information}

ABSTRACT: To evaluate the potential effects of antibiotics on ammoniaoxidizing microbes, multiple tools including quantitative PCR (qPCR), 454pyrosequencing, and a high-throughput functional gene array (GeoChip) were used to reveal the distribution of ammonia-oxidizing archaea (AOA) and archaeal amoA (Arch-amoA) genes in three wastewater treatment systems receiving spiramycin or oxytetracycline production wastewaters. The qPCR results revealed that the copy number ratios of Arch-amoA to ammonia-oxidizing bacteria $(\mathrm{AOB})$ amoA genes were the highest in the spiramycin full-scale $(5.30)$ and pilot-scale systems $\left(1.49 \times 10^{-1}\right)$, followed by the oxytetracycline system $\left(4.90 \times 10^{-4}\right)$, with no Arch-amoA genes detected in the control systems treating sewage or inosine production wastewater. The pyrosequencing result showed that the relative abundance of AOA affiliated with Thaumarchaeota accounted for $78.5-99.6 \%$ of total archaea in the two spiramycin systems, which was in accordance with the qPCR results. Mantel test based on GeoChip data showed that Arch-amoA gene signal intensity correlated with the presence of spiramycin $(P<0.05)$. Antibiotics explained $25.8 \%$ of variations in $a m o A$ functional gene structures by variance partitioning analysis. This study revealed the selection of AOA in the presence of high concentrations of spiramycin in activated sludge systems.

\section{INTRODUCTION}

Before the discovery of archaeal ammonia monooxygenase (Arch-amoA) genes ${ }^{1,2}$ and ammonia-oxidizing archaeal isolates, ${ }^{3,4}$ ammonia-oxidizing bacteria $(\mathrm{AOB})$ were thought to be the sole group of microorganisms performing oxidation of ammonia to nitrite. ${ }^{5}$ It has become clear, however, that environmental nitrogen cycling is driven by both ammoniaoxidizing archaea (AOA) and $\mathrm{AOB}{ }^{6}$ Recent studies have shown that autotrophic ammonia oxidation in soils is driven mainly by $\mathrm{AOA}$ rather than $\mathrm{AOB}$ under certain extreme conditions, such as low ammonia concentration ${ }^{7}$ and low $\mathrm{pH}$ $(\mathrm{pH}<4.50)^{8}$

The presence of Arch-amoA and AOA in wastewater treatment plants (WWTPs) has been reported in many countries. $^{9-17}$ In most cases, however, the numbers of ArchamoA were 1-3 orders of magnitude lower than those of AOB $^{11,18}$ In a study of 17 industrial and 35 municipal European WWTPs, ${ }^{18}$ only four industrial WWTPs were found to harbor AOA using catalyzed reporter deposition-fluorescence in situ hybridization (CARD-FISH). In one petroleum refinery WWTP, where AOA outnumbered AOB up to 10000 fold, AOA did not exhibit autotrophic activity in the presence of ammonia. Thus, $\mathrm{AOB}$ are considered the main agents driving nitrification in most WWTPs, ${ }^{5}$ because the relatively high ammonia concentrations in normal suspended growth wastewater treatment systems may preclude the growth of AOA. ${ }^{19}$

However, the situation may change when the biological processes are used for treating antibiotic production wastewater containing high concentrations of antibiotics. ${ }^{20,21}$ Because of their adverse effects on bacteria, antibiotics might provide the advantage of AOA over AOB in WWTPs. ${ }^{22,23}$ On the basis of

Received: March 13, 2015

Revised: May 30, 2015

Accepted: June 30, 2015

Published: June 30, 2015 
this assumption, quantitative PCR (qPCR) and 454-pyrosequencing were jointly employed to reveal the relative abundance of AOA and Arch-amoA genes over AOB and AOB amo $A$ genes in three antibiotic (two spiramycin and one oxytetracycline) production wastewater treatment systems with stable nitrification performance. At the same time, a high throughput functional gene array (GeoChip) was used to reveal the changes of nitrogen cycling functional genes in these WWTPs. Two municipal wastewater treatment plants and an inosine production wastewater treatment plant were used as the control systems. Our results indicated that Arch-amoA genes for nitrification were of high abundance in the spiramycin wastewater treatment system.

\section{MATERIALS AND METHODS}

Study Facilities, Sampling Sites, and Characterization of Samples. Six wastewater treatment systems, including three antibiotic production wastewater treatment systems and three control (two sewage and one inosine) ones were chosen for this study. The schematic flow diagrams of the three antibiotic systems are shown in Supporting Information Figure S1. Three antibiotic wastewater treatment systems, including two spiramycin production wastewater treatment systems (pilot system and full-scale system) in Wuxi Fortune Pharmaceutical Co. Ltd. and a full-scale oxytetracycline production wastewater treatment system in North China Pharmaceutical Group Corporation, were used for this study. Wuxi Fortune Pharmaceutical Co. Ltd., Wuxi City, China, is one of the largest spiramycin production facilities in the world. The fullscale spiramycin wastewater treatment plant, consisting of anoxic reactor and oxidation ditch (OD) processes with returned sludge, has been in use since 2005. Water samples were collected using an automated sampler over three successive days, and included full-scale influent (SPM(F)$\mathrm{W} 1)$, full-scale anoxic effluent (SPM(F)-W2), and full-scale final effluent (SPM(F)-W3) (Supporting Information Figure S1a). Grab sludge samples from full-scale OD sludge (SPM(F)S1) were taken from the OD reactor (Supporting Information Figure S1a). The hydraulic retention time (HRT) and sludge retention time (SRT) were 2.5 and 7 days, respectively.

Samples were also collected from a pilot-scale wastewater treatment system in Wuxi Fortune Pharmaceutical Co. Ltd. The system, consisting of a sequential up-flow anaerobic sludge bed (UASB), anoxic reactor, and oxic reactor with returned sludge (Supporting Information Figure S1b), was operated for 9 months and is described in detail in our previous study. ${ }^{24}$ System operation was divided into three stages: (i) receiving spiramycin wastewater, (ii) receiving spiramycin wastewater and paromomycin wastewater, and (iii) receiving spiramycin wastewater and ribostamycin wastewater. Each stage lasted 3 months. Raw wastewater and effluent from each treatment unit of the pilot system (pilot-scale influent $\left(\operatorname{SPM}(\mathrm{P})-\mathrm{W} 1_{1-3}\right)$, pilotscale anoxic effluent $\left(\mathrm{SPM}(\mathrm{P})-\mathrm{W} 2_{1-3}\right)$, and (pilot-scale aerobic effluent $\left.\left(\operatorname{SPM}(\mathrm{P})-\mathrm{W} 3_{1-3}\right)\right)$ were collected at the end of each stage (Supporting Information Figure S1b). Aerobic sludge samples ( $\mathrm{SPM}(\mathrm{P})-\mathrm{S} 1_{1-3}$ for three stages, respectively) were collected from the aerobic reactor once at the end of each stage.

Over 1000 tons of oxytetracycline is produced every year in the North China Pharmaceutical Group Corporation, which is located in Shijiazhuang City, China. Water and sludge samples were collected in the full-scale wastewater treatment system, which consists of a sequential batch reactor (SBR) (OTC-S1, SBR sludge; OTC-W1, SBR influent; OTC-W2, SBR effluent) and a two-stage submerged biological contact reactor using fiber bundles as the biocarrier with returned sludge (OTC-S2, biological contact reactor sludge; OTC-W3, final effluent) (Supporting Information Figure S1c). A detailed description of the oxytetracycline wastewater treatment system is described in our previous study. ${ }^{25}$ All samples were transported to the lab at $4{ }^{\circ} \mathrm{C}$ and treated within $24 \mathrm{~h}$. No rain events were registered during the sampling days or the previous week.

For comparison, aerobic activated sludge samples from two municipal wastewater treatment plants located in Beijing (Sewage-S1; anaerobic/anoxic/aerobic system (A2O) $)^{26}$ and Tianjin (Sewage-S2; A2O), respectively, and an inosine production wastewater treatment plant (Inosine-S cyclic activated sludge system) in Xinxiang City, Henan, China, ${ }^{27}$ were collected as controls. The wastewater samples were taken exclusively for chemical characterization, whereas the sludge samples were taken for molecular analysis. The concentrations of antibiotics including spiramycin, oxytetracycline, and penicillin $G$, in the wastewater and sludge were determined using ultra performance liquid chromatography tandem mass spectrometry (UPLC-MS/MS, Waters, USA), as described previously. ${ }^{21,24,25,28}$ Ammonia and other chemical properties were measured according to the Standard Method of Water and Wastewater Monitoring ${ }^{29}$ on the same samples. All samples were analyzed for chemical properties in triplicate and average values were reported.

DNA Extraction and Quantitative PCR. For each sludge sample, $1 \mathrm{~mL}$ of mixed liquor was centrifuged at $12000 \mathrm{~g}$ for 10 $\min$ at $4{ }^{\circ} \mathrm{C}$. After centrifugation, $0.25 \mathrm{~g}$ of sediment (wet weight) was used for DNA extraction using a FastDNA SPIN kit for soil (Qbiogene, Solon $\mathrm{OH}$ ) according to the manufacturer's instructions. For each sample, DNA was extracted in duplicate, and extracts from the same sample were pooled to avoid bias in DNA extraction efficiency. The DNA solution volume was $80 \mu \mathrm{L}$, of which $2 \mu \mathrm{L}$ was used for concentration determination by NanoDrop ND-1000 (Nanodrop, USA) and $5 \mu \mathrm{L}$ was checked by electrophoresis on $1 \%$ (weight/volume) agarose gel.

Bacterial and archaeal 16S rRNA, Arch-amoA, and AOB $a m o A$ genes were quantified for all sludge samples using SYBRGreen real-time PCR, as described previously. ${ }^{30-33}$ The archamoA, AOB amoA, archaeal and bacterial 16S rRNA gene targets were amplified by the primer sets Arch-amoAF/ArchamoAR, amoA-1F/amoA-2R, 349F/806R, and 341F/534R, respectively (Supporting Information Table S1). Standard plasmids carrying the target amplicons were obtained by PCR and TA cloning (Invitrogen, San Diego, CA), followed by extraction using a Qiagen Plasmid Mini kit (Qiagen, Germany). Concentrations of standard plasmids (ng $\mu \mathrm{L}^{-1}$ ) were determined with the Nanodrop ND-1000 spectrophotometer.

The $25 \mu \mathrm{L}$ real-time PCR reactions typically contained $1 \times$ Sybr Green I, $1 \times$ Dye (Takara), $200 \mathrm{nM}$ of each primer, $0.5 \mathrm{mg}$ $\mathrm{mL}^{-1}$ of BSA, and $2 \mu \mathrm{L}$ of DNA templates. Real-time PCR was run on an ABI7300 apparatus (ABI, USA) with the following program: $95{ }^{\circ} \mathrm{C}$ for $30 \mathrm{~s}, 40$ cycles consisting of: (i) $95{ }^{\circ} \mathrm{C}$ for $10 \mathrm{~s}$, (ii) annealing temperature for $12 \mathrm{~s}$, (iii) $72{ }^{\circ} \mathrm{C}$ for $12 \mathrm{~s}$, and (iv) $82{ }^{\circ} \mathrm{C}$ for $26 \mathrm{~s}$ to collect the fluorescent signals, with the melting process automatically generated by ABI7300 software. Triplicate assays were performed for decimally diluted standard plasmids, properly diluted samples and negative controls (sterile water).

To prevent the inhibition of the sample matrix, 10- to 100 fold diluted samples were used for quantification. The following 
requirements were satisfied to obtain reliable quantification (Supporting Information Table S2): Standard curves covered 5-8 orders of magnitude, with $R^{2}$ higher than 0.99 and amplification efficiencies based on slopes between $90 \%$ and $110 \%$. Specificity was assured by the melting curves analysis and agarose gel electrophoresis. All qPCR protocols and data analyses were performed within the standards outlined by the MIQE guidelines. ${ }^{34}$

454 Pyrosequencing. For 454-pyrosequencing, archaeal 16S rRNA genes were amplified with primers Arch344F (5'ACGGGGYGCAGCAGGCGCGA-3') and Arch915R (5'GTGCTCCCCCGCCAATTCCT- $\left.3^{\prime}\right)$. $^{31}$ Barcodes that allowed sample multiplexing during pyrosequencing were incorporated between the 454 adapter and forward primers. ${ }^{35}$ The length of the amplicon, including the barcode and 454 primers, was $\sim 596$ nt. The PCR mixtures $(50 \mu \mathrm{L})$ were prepared in triplicate and each contained $0.6 \mu \mathrm{M}$ of each primer, $\sim 5 \mathrm{ng}$ of template DNA, 1× PCR reaction buffer, and $2.5 \mathrm{U}$ of Pfu DNA polymerase. The PCR reactions were performed as described previously. ${ }^{36}$ The PCR products of archaea were purified and then sequenced by pyrosequencing on a 454 Life Sciences Genome SequencerFLX (Roche Diagnostics, Indianapolis, IN, USA) machine. Raw pyrosequencing data obtained from this study were deposited in the NCBI Sequence Read Archive (SRA, http://trace.ncbi.nlm.nih.gov/Traces/sra/sra.cgi?) with accession No. SRP058669.

The complete sequence reads were analyzed using mothur software. ${ }^{37}$ Briefly, raw sequence reads were first filtered to remove the sequences with quality scores below 25 . The multiplexed reads were assigned to samples based on their nucleotide barcodes. Thereafter, low quality sequence reads have been removed based on following criteria: (i) not perfectly matching the proximal PCR primer; (ii) less than $200 \mathrm{bp}$ for archaea; (iii) homopolymers longer than six nucleotides; (iv) with one or more ambiguous base(s), or flagged as chimeric artifacts checked by UCHIME (http://drive5.com/uchime). The remaining sequences were trimmed and aligned against the silva database (version: SSU111 http://www.arb-silva.de/) using k-mer searching (http://www.mothur.org/wiki/Align. seqs). The sequences were then clustered into operational taxonomic units (OTUs, 97\% similarity) using the furthest neighbor method (http://www.mothur.org/wiki/Cluster). Taxonomic classification down to phylum, class, order, family, and genus was performed using mothur (http://www.mothur. org/wiki/Classify.seqs) via the silva database and the algorithm of the naive bayesian classifier ${ }^{38}$ with a confidence threshold of $80 \%{ }^{39}$ Rarefaction curves and the Simpson and Shannondiversity indices ${ }^{40,41}$ were also generated for each sample.

GeoChip Analyses. Community DNA for GeoChip analyses was extracted using a freeze-grinding method, which has long been adopted for DNA extraction during Geochip analysis, as described previously. ${ }^{42}$ The latest generation of functional gene array, GeoChip 5.0 (manufactured by Agilent Technologies Inc., Santa Clara, CA), was used to analyze the functional structure of the sludge microbial communities. GeoChip 5.0 contained more than 57000 oligonucleotide probes, covering over 144000 gene sequences from 393 gene families. This includes the 19 main functional gene groups involved in $\mathrm{N}$ cycling, such as nitrification (amoA, hao), denitrification (narG, nirK, nirS, norB, nosZ), and nitrogen fixation (nifH). Purified sludge DNA $(0.5 \mathrm{mg}$ ) was used for GeoChip hybridization, which was labeled with $\mathrm{Cy} \mathrm{3,} \mathrm{as}$ described before. Before hybridization, the labeled DNA was resuspended and hybridized with GeoChip. The hybridization solution (42 mL in total) contained $1 \times$ HI-RPM hybridization buffer, $1 \times$ aCGH blocking agent, $0.05 \mathrm{mg} / \mathrm{mL}$ of Cot- 1 DNA, 10 pM universal standard DNA, and $10 \%$ formamide (final concentrations). GeoChip hybridization was carried out at 67 ${ }^{\circ} \mathrm{C}$ in an Agilent hybridization oven for $24 \mathrm{~h}$. After hybridization, the slides were washed with Agilent wash buffers at room temperature. The arrays were then scanned with a NimbleGen MS200 Microarray Scanner (Roche NimbleGen, Inc., Madison, WI, USA) at $633 \mathrm{~nm}$ using a laser power of $100 \%$ and a photomultiplier tube gain of $75 \%$. The images were extracted by the Agilent Feature Extraction program. The microarray data were preprocessed for subsequent analysis, as described previously ${ }^{43,44}$ in terms of poor and outlying spot removal, background subtraction, normalization and sample.

Statistical Analysis. Wastewater and sludge properties were standardized prior to analysis using the formula, $z=\left(x_{i}-\right.$ $\bar{x}) / s$, where $x_{i}$ is the sample value, $\bar{x}$ is the mean of all samples, and $s$ is the standard deviation. ${ }^{25,45}$ Mantel tests were used to examine the relationships between the abundance of functional genes and the antibiotic concentrations in ten samples from the biological antibiotic production wastewater treatment systems. ${ }^{46}$ The standardized GeoChip data for the gene categories (and families) of each sample was set as the first matrix, and the normalized wastewater and sludge data of each sample was set as the second matrix. Canonical correspondence analysis (CCA) was used to discern possible linkages between microbial community functional structures and water properties in sludge samples from the six wastewater treatment systems, and partial CCA was used to analyze the contributions of different chemical water variables to microbial functional structures. Mantel tests, ANOVA analysis (Analysis of Variance), CCA, and partial CCA were performed using R 2.13.1 (http://www.rproject.org/) with the vegan and stats packages. Significance tests were conducted by Monte Carlo permutation (999 times). $P$ values $<0.05$ were regarded as significant. All microarray hybridization data are available at the Institute for Environmental Genomics, University of Oklahoma (http://ieg.ou.edu).

\section{RESULTS}

Characterization of Wastewater and Sludge. Detailed chemical characteristics of wastewater and sludge (Supporting Information Table S3 and Table S4), including chemical oxygen demand (COD) and antibiotic concentrations for the spiramycin pilot-scale system and the oxytetracycline system, are described in our previous studies. ${ }^{24,25}$ In the full-scale system, the spiramycin concentrations of the influent (SPM(F)W1), anoxic effluent (SPM(F)-W2), and final effluent (SPM(F)-W3) were 236, 216, and $6.15 \mathrm{mg} / \mathrm{L}$, respectively, which were much higher than those in the pilot system. ${ }^{24}$ The spiramycin concentration in aerobic sludge (SPM(F)-S) reached $580 \mathrm{mg} / \mathrm{kg}$ dry weight, which was much higher than that in the pilot-scale system $(24.5-114 \mathrm{mg} / \mathrm{kg}$ dry weight for $\left.\operatorname{SPM}(\mathrm{P})-\mathrm{S}_{1}-\mathrm{S}_{3}\right)$. Though fluoroquinolones, tetracyclines, sulfonamides, macrolides and other antibiotics have been detected in sewage in many countries, the total antibiotic concentrations are in general below several $\mu \mathrm{g} / \mathrm{L},{ }^{47}$ which are several orders lower than those detected in antibiotic production wastewater. The COD concentration decreased from 4575 to $601 \mathrm{mg} / \mathrm{L}$ in the full-scale spiramycin system. The ammonia concentrations decreased from $61.5,249$, and $164 \mathrm{mg} / \mathrm{L}$ to $8.49,8.90$, and 5.07 $\mathrm{mg} / \mathrm{L}$ in the spiramycin full-scale, pilot-scale, and oxytetracycline systems, respectively. The ammonia removals in 
Table 1. Relative Abundances of Arch-amoA and AOB amoA Genes in Activated Sludge Samples from Different Systems ${ }^{a}$

\begin{tabular}{|c|c|c|c|c|c|}
\hline $\begin{array}{l}\text { wastewater treatment } \\
\text { system }\end{array}$ & sample code & $\begin{array}{c}\text { Arch-amoA gene copy numbers } \\
\text { (ng DNA) }\end{array}$ & $\begin{array}{c}\mathrm{AOB} a m o A \text { gene copy numbers } \\
\text { (ng DNA) }\end{array}$ & $\begin{array}{c}\text { ratio of } \\
\text { Arch- } a m o A / A O B ~ a m o A\end{array}$ & $\begin{array}{c}\text { average ratio of } \\
\text { Arch-amoA/AOB amoA }\end{array}$ \\
\hline spiramycin full-scale & $\operatorname{SPM}(\mathrm{F})-\mathrm{S}$ & $\begin{array}{l}1.72 \times 10^{5} \\
\left(3.02 \times 10^{5}\right)\end{array}$ & $\begin{array}{l}3.25 \times 10^{4} \\
\left(3.17 \times 10^{2}\right)\end{array}$ & 5.30 & 5.30 \\
\hline \multirow[t]{3}{*}{$\begin{array}{l}\text { spiramycin pilot- } \\
\text { scale }\end{array}$} & $\operatorname{SPM}(\mathrm{P})-\mathrm{S}_{1}$ & $\begin{array}{l}2.56 \times 10^{3} \\
\left(7.85 \times 10^{1}\right)\end{array}$ & $\begin{array}{l}2.22 \times 10^{4} \\
\left(2.56 \times 10^{3}\right)\end{array}$ & $1.15 \times 10^{-1}$ & $1.49 \times 10^{-1}$ \\
\hline & $\operatorname{SPM}(\mathrm{P})-\mathrm{S}_{2}$ & $\begin{array}{l}1.39 \times 10^{4} \\
\left(3.25 \times 10^{3}\right)\end{array}$ & $\begin{array}{l}4.47 \times 10^{4} \\
\left(3.84 \times 10^{3}\right)\end{array}$ & $3.12 \times 10^{-1}$ & \\
\hline & $\operatorname{SPM}(\mathrm{P})-\mathrm{S}_{3}$ & $\begin{array}{l}4.69 \times 10^{2} \\
\left(2.54 \times 10^{1}\right)\end{array}$ & $\begin{array}{l}2.40 \times 10^{4} \\
\left(6.00 \times 10^{3}\right)\end{array}$ & $1.95 \times 10^{-2}$ & \\
\hline \multirow[t]{2}{*}{$\begin{array}{l}\text { oxy-tetracycline full- } \\
\text { scale }\end{array}$} & OTC-S1 & $\begin{array}{l}3.60 \times 10^{1} \\
\left(3.00 \times 10^{1}\right)\end{array}$ & $\begin{array}{l}3.90 \times 10^{4} \\
\left(1.94 \times 10^{3}\right)\end{array}$ & $9.22 \times 10^{-4}$ & $4.90 \times 10^{-4}$ \\
\hline & OTC-S2 & $\begin{array}{l}1.66 \times 10^{1} \\
\left(5.65 \times 10^{\circ}\right)\end{array}$ & $\begin{array}{l}2.84 \times 10^{5} \\
\left(3.25 \times 10^{4}\right)\end{array}$ & $5.84 \times 10^{-5}$ & \\
\hline \multirow[t]{2}{*}{ sewage full-scale } & Sewage-S1 & $\mathrm{UD}^{b}$ & $\begin{array}{l}2.66 \times 10^{4} \\
\left(7.32 \times 10^{3}\right)\end{array}$ & UD & UD \\
\hline & Sewage-S2 & UD & $\begin{array}{l}3.53 \times 10^{3} \\
\left(5.55 \times 10^{2}\right)\end{array}$ & UD & \\
\hline $\begin{array}{l}\text { non-antibiotic full- } \\
\text { scale }\end{array}$ & Inosine-S & UD & $\begin{array}{l}4.21 \times 10^{3} \\
\left(1.51 \times 10^{3}\right)\end{array}$ & UD & UD \\
\hline
\end{tabular}

the aerobic reactors were $92.8-97.0 \%$, showing that nitrification functioned well in these three systems (Supporting Information Table S3).

Quantification of Arch-amoA and AOB amoA Genes Using qPCR. AOA and $A O B$ abundances were inferred by qPCR of the amoA gene, which encodes subunit A of ammonia monooxygenase that performs the first step in ammonia oxidation by both groups. Table 1 shows copy number ratios of Arch-amoA to AOB $a m o A$ genes in the activated sludge samples from different systems. Interestingly, the average ratios of the Arch-amoA/AOB amoA genes were 5.30, $1.49 \times 10^{-1}$ and $4.90 \times 10^{-4}$ for the spiramycin full-scale, pilot-scale and oxytetracycline systems, respectively, whereas no Arch-amoA genes were detected in the sewage and inosine systems (Table 1).

Arch-amoA and AOB amoA gene copy numbers were normalized to DNA concentrations (ng DNA) (Table 1) and archaeal and bacterial 16s rRNA genes (Supporting Information Table S5), respectively, for comparison. The AOB amoA gene abundances in the six different wastewater treatment systems varied between $3.53 \times 10^{3}$ and $4.47 \times 10^{4}$ gene copies per ng of DNA, and between $6.21 \times 10^{-3}$ and 1.21 normalized to bacterial 16s rRNA genes, respectively. The Arch-amoA genes for the three antibiotic systems, on the other hand, varied from $1.66 \times 10^{1}$ to $1.75 \times 10^{5}$ gene copies per ng of DNA and from $1.78 \times 10^{-2}$ to 1.14 normalized to archaeal $16 \mathrm{~s}$ rRNA genes, respectively.

Archaeal and Bacterial Community Revealed by 454Pyrosequencing Analysis. Archaeal and bacterial compositions were revealed by 454-pyrosequencing. Good's coverage ranged from 95.7 to $97.9 \%$ for archaea and from $89.0 \%$ to $96.0 \%$ for bacteria, respectively. The Shannon indices of archaea (3.23-3.34) were lower than that of bacteria (4.306.01), whereas the Simpson (0.0104-0.0538 for bacteria, and 0.1073-0.2946 for archaea) indices showed the reverse trends (Supporting Information Table S6 and Table S7).
Figure 1 shows the relative abundances of the archaeal community at the phylum level for each sample. Interestingly,

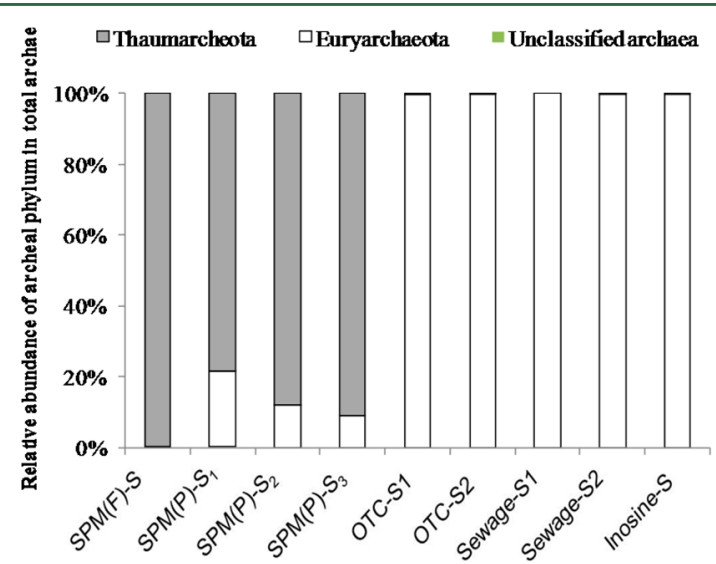

Figure 1. Relative archaeal community abundance at the phylum level of sludge samples.

the relative abundance of Thaumarchaeota in archaeal population was $99.60 \%$ in full-scale spiramycin system, followed by 78.52 to $91.00 \%$ ( $85.81 \%$ in average $)$ in pilot-scale spiramycin system. The only AOA phylotype detected in the three antibiotic systems (at the genus level) was identified as Candidatus Nitrososphaera belonging to Thaumarcheota group I. $1 \mathrm{~b} \mathrm{AOA}^{4}$ On the contrary, the abundance of Euryarchaeota in archaea was $>99 \%$ in the oxytetracycline, sewage, and inosine systems (Supporting Information Table S8 and Table S9).

Supporting Information Table S10 summarized the relative bacterial community abundance at the phylum level for each sample. It was clear that the presence of antibiotics did not affect the bacterial community structures significantly in the phylum or class level. Proteobacteria was the most abundant phylum (30.35 to $50.89 \%)$ in all of the systems, with $\alpha$ - (6.20 to $18.98 \%$ ) and $\beta$-proteobacteria (13.31 to $34.76 \%$ ) as the two 
Table 2. Total AOA and AOB amoA Gene Log Transformed Signal Intensities from by Using GeoChip 5.0 and the Ratio of AOA and AOB amoA Gene Signal Intensities (Arch-amoA/AOB amoA) of Activated Sludge Samples from Antibiotic, Sewage, and Inosine Wastewater Biological Treatment Systems

\begin{tabular}{|c|c|c|c|c|c|c|c|c|c|}
\hline \multirow{2}{*}{ total signal intensity of $a m o A$ genes } & \multirow{2}{*}{$\frac{\text { spiramycin full-scale }}{\operatorname{SPM}(F)-S}$} & \multicolumn{3}{|c|}{ spiramycin pilot-scale } & \multicolumn{2}{|c|}{ oxytetracycline } & \multicolumn{2}{|c|}{ sewage } & \multirow{2}{*}{$\frac{\text { inosine }}{\text { Inosine-S }}$} \\
\hline & & $\operatorname{SPM}(\mathrm{P})-\mathrm{S}_{1}$ & $\operatorname{SPM}(\mathrm{P})-\mathrm{S}_{2}$ & $\operatorname{SPM}(\mathrm{P})-\mathrm{S}_{3}$ & OTC-S1 & OTC-S2 & Sewage-S1 & Sewage-S2 & \\
\hline Arch-amoA & 11.88 & 22.21 & 19.46 & 22.26 & 22.11 & 22.56 & 20.64 & 20.75 & 18.57 \\
\hline $\mathrm{AOB}$ amoA & 3.86 & 20.73 & 18.26 & 21.75 & 22.00 & 21.08 & 20.97 & 22.86 & 20.95 \\
\hline Arch-amoA /AOB amoA & 3.08 & 1.07 & 1.07 & 1.02 & 1.01 & 1.07 & 0.98 & 0.91 & 0.89 \\
\hline average Arch-amoA /AOB amoA & 3.08 & & 1.05 & & & & & 95 & 0.89 \\
\hline
\end{tabular}

Table 3. Relationship between amoA Genes (GeoChip) for Ammonia Oxidation and Water Characteristics Revealed by Mantel Test

\begin{tabular}{|c|c|c|c|c|c|c|c|c|c|c|}
\hline \multirow[b]{2}{*}{ gene category } & \multicolumn{2}{|c|}{$\begin{array}{l}\text { total water characteristics } \\
\left(\text { antibiotics, } \mathrm{COD}, \mathrm{NH}_{4}^{+}\right)\end{array}$} & \multicolumn{2}{|c|}{ total antibiotics } & \multicolumn{2}{|c|}{ spiramycin } & \multicolumn{2}{|c|}{ oxytetracycline } & \multicolumn{2}{|c|}{$\mathrm{NH}_{4}^{+}$} \\
\hline & $r_{M}$ & $P$ & $r_{\mathrm{M}}$ & $P$ & $r_{\mathrm{M}}$ & $P$ & $r_{M}$ & $P$ & $r_{\mathrm{M}}$ & $P$ \\
\hline total $a m o A$ & 0.408 & 0.143 & 0.509 & 0.115 & 0.855 & 0.057 & -0.004 & 0.360 & 0.352 & 0.051 \\
\hline Arch-amoA & 0.366 & 0.133 & 0.496 & 0.066 & 0.710 & 0.019 & 0.105 & 0.320 & 0.274 & 0.082 \\
\hline AOB amoA & 0.372 & 0.138 & 0.450 & 0.125 & 0.791 & 0.084 & -0.045 & 0.466 & 0.328 & 0.056 \\
\hline
\end{tabular}

${ }^{a_{T}}$ The signal intensity of genes among nigh samples from biological treatment systems was used as the first matrix; the normalized water characteristics were used as the second matrix. Bold values indicate significant $P$-values $(<0.05)$.

most abundant classes. The other major phyla include Chloroflexi (6.66 to $32.27 \%)$, Bacteroidetes (2.14 to $28.11 \%$ ), Actinobacteria (1.72 to $15.19 \%)$, Acidobacteria (0.02-16.32\%), Planctomycetes ( 0.34 to $6.89 \%)$, etc. This result was in accordance with our previous study showing that the presence of antibiotics did not affect bacterial diversity much. ${ }^{25}$ However, it seemed that the presence of high concentrations of antibiotics favored the growth of Gemmatimonadetes and Deinococcus-Thermus.

Nitrogen-Cycling Genes and amoA Genes Detected by GeoChip. A total of 2670 nitrogen cycling functional genes were detected by GeoChip for all activated sludge samples from the three antibiotic wastewater treatment systems and three control wastewater treatment systems. There were 80 genes for nitrification, 1223 genes for denitrification, four genes for anaerobic ammonium oxidation (anammox), 222 genes for assimilatory nitrate/nitrite reduction, 396 nif $\mathrm{H}$ genes for nitrogen fixation, 173 genes for dissimilatory nitrogen reduction, 413 genes for ammonification and 159 genes for assimilation (Supporting Information Table S11).

Eighty nitrification genes, including $65 \mathrm{amo} A$ and 15 hao genes, were detected. Among the 65 amoA genes, 38 were derived from bacteria belonging to uncultured bacteria ( 28 genes), $\beta$-proteobacteria (8 genes), and $\gamma$-proteobacteria (two genes), respectively, whereas 27 were derived from AOA (most affiliated with Thaumarcheota) (Supporting Information Table S12). ANOVA analysis of $a m o A$ genes showed that the four activated sludge groups (spiramycin, oxytetracycline, sewage, and inosine systems) had significant difference $(P<0.05)$. The spiramycin full-scale system exhibited the highest average signal intensity ratios of Arch-amoA to AOB amoA genes (3.08), followed by the spiramycin pilot-scale (average: 1.05), oxytetracycline (average: 1.04), sewage (average: 0.91), and inosine (0.89) systems, suggesting the selection effects of antibiotics for Arch-amoA, particularly in the spiramycin fullscale system (Table 2).

Mantel tests were performed to examine the relations between the signal intensity of function genes (GeoChip) and antibiotic concentration in the wastewater treatment systems. The relationships between the abundance of total
amoA, Arch-amoA, and AOB amoA genes and total antibiotic concentrations or ammonia concentration were not significant $(P>0.05)$. However, the Arch-amoA genes were significantly correlated with spiramycin concentration $(r=0.780, P=0.019)$ (Table 3: in bold face). For bacteria, no significant correlation was observed between the $\mathrm{AOB}$ amoA genes and spiramycin concentration.

Contributions of Water Quality Variables to Variations in N-Cycling and Nitrification Functional Gene Structures. CCA was performed to discern possible linkages between microbial functional structure related to nitrification (amoA gene)/nitrogen-cycling functional genes and water variables in the activated sludge samples (Supporting Information Figure S2a,b). The best combination of four water quality variables (spiramycin, oxytetracycline, COD, and ammonia concentrations) were included in the CCA biplot based on automatic forward selection, variance inflation factors with 999 Monte Carlo permutations, and the previous evidence. $^{25}$ The first axis, which was positively correlated with oxytetracycline, explained $38.0 \%$ of the amoA diversity observed, and the second axis, which was negatively correlated with spiramycin, COD, and ammonia, explained $24.4 \%$ of the total variation. The contributions of antibiotics (A) (spiramycin and oxytetracycline), COD (C), and ammonia (N) on amoA and nitrogen-cycling functional structure variations were determined with variance partitioning analysis (VPA) using partial CCA (Figure 2 and Supporting Information Figure S3, respectively). Total variation was partitioned into the pure effects of $\mathrm{A}, \mathrm{C}$, and $\mathrm{N}$, interactions between any two components $(\mathrm{A} \times \mathrm{C}, \mathrm{A} \times \mathrm{N}$, and $\mathrm{N} \times \mathrm{C})$, common interactions between all three components $(\mathrm{A} \times \mathrm{N} \times \mathrm{C})$ and the unexplained portion (Figure 2a). Totals of $55.3 \%$ and $54.3 \%$ of the variation of $a m o A$ and nitrogen-cycling functional structures were significantly explained $(P<0.05)$ by the three components, respectively (Figure $2 \mathrm{~b}$ and Supporting Information Figure S3b). Antibiotics, COD and ammonia independently explained 25.8, 10.6, and $10.8 \%$ of total variations observed in amoA genes, and 29.2, 11.6, and $11.5 \%$ of total variations observed in nitrogen-cycling, respectively. It should 


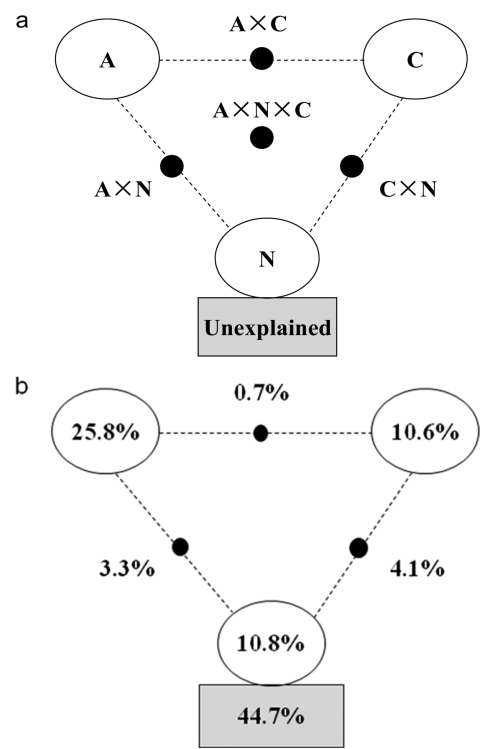

Figure 2. Variation partitioning analysis of amoA gene diversity by GeoChip explained by antibiotics (A), COD (C), and $\mathrm{NH}_{4}^{+}(\mathrm{N})$. (a) General outline, (b) amoA genes. Each diagram represents the biological variation partitioned into the relative effects of each variable or a combination of variables, in which geometric areas are proportional to the respective percentages of explained variation. The edges of the triangle represent the variation explained by each variable alone. The sides of the triangles represent interactions of any two variables and the middle of the triangles represents the interaction of all three variables.

be noted that the VPA results were acquired based on limited sample size (nine activated samples).

\section{DISCUSSION}

Nitrification is a key and often rate-limiting step in nitrogen removal. ${ }^{10}$ Previous batch test results have shown that the presence of antibiotics can inhibit nitrification. ${ }^{22,48}$ However, we observed sound nitrification in all three biological systems treating antibiotic-containing wastewater (Supporting Information Table S3). By employing qPCR, 454-pyrosequencing and GeoChip analysis, we demonstrated that Arch-amoA genes as well as AOA (C. Nitrososphaera) were of high abundance in the full-scale spiramycin systems (Table 1, Table 2, and Figure 1). Although the AOB amoA copy numbers per ng DNA in the spiramycin systems $\left(3.5 \times 10^{3}-2.8 \times 10^{5}\right.$ copies/ng DNA $)$ were similar to or higher than those in a saline nitrification reactor $\left(4.7 \times 10^{3}-2.3 \times 10^{5}\right.$ copies $/$ ng DNA $)$ and rotating biological contactors treating municipal wastewater (approximately $>2 \times 10^{2}-1.2 \times 10^{3}$ copies/ng DNA or approximately $<7.2 \times 10^{3}$ copies/ng DNA, estimated from graphs), ${ }^{19,49,50}$ Arch-amoA gene numbers in the two spiramycin systems $(4.7 \times$ $10^{2}-1.7 \times 10^{5}$ copies/ng DNA) were higher than those in the above studies $\left(1.7 \times 10^{2}-3.8 \times 10^{3}\right.$ copies $/ \mathrm{ng}$ DNA; approximately $<1 \times 10^{2}-7 \times 10^{2}$ copies/ng DNA, approximately $<2.3 \times 10^{2}$ copies $/ \mathrm{ng} \mathrm{DNA}$, estimated from graphs). ${ }^{19,49,50}$ Thus, AOA may play an important role in the nitrification of the spiramycin systems. However, the high ratio of Arch-amoA to AOB amoA genes in the spiramycin systems was not driven by the decrease in AOB amoA but rather by an increase in Arch-amoA genes (Table 1 and Table 2). In fact, high thresholds of antibiotic resistance were observed in the spiramycin and oxytetracycline systems in our previous studies. $^{24,25,27}$ Thus, it was possible that AOB could survive by acquiring antibiotic resistance through long-term exposure and would keep the position as the key player in ammonia removal.

The niches of AOA within the nitrogen cycle have been deducted to be low-nutrient, low- $\mathrm{pH}$, and sulfide-containing environments, ${ }^{6,51}$ which are generally not the case for municipal wastewater treatment employing suspended growth systems. ${ }^{19}$ That might be the reason why most previous studies reported low or zero Arch-amoA gene abundance in WWTPs. ${ }^{11,12,14}$ Since the first report on the presence of AOA in WWTPs, quite a few studies have investigated the contribution of AOA in wastewater nitrification. ${ }^{11}$ Most reported that the copy numbers of Arch-amoA genes were much lower than those of AOB in many cases. ${ }^{11,18}$ One definitive study depicted a ratedependent negative correlation between ammonium concentration and the relative abundance of AOA amoA genes in rotating biological contactors. ${ }^{19}$ In another study of European WWTPs, three petroleum refinery WWTPs exhibited high abundance of Thaumarchaeota carrying amoA. ${ }^{18}$ Using FISH in combination with microautoradiography (MAR) with ${ }^{14} \mathrm{C}$ inorganic carbon labeling, AOA closely related to Thaumarchaeota soil group I.1b were associated with degradation of organic compounds, rather than performing autotrophic nitrification in one petroleum refinery WWTP. ${ }^{18}$ High ratios of AOA to AOB amoA gene copy numbers (5.10 to 95.5) and group I.1b Thaumarchaeota were also found in some wells of petroleum reservoirs, ${ }^{52}$ suggesting that petroleum reservoirs might be a source of AOA. The high abundance of AOA or Arch-amoA genes observed in some WWTPs might originate from the inflow of wastewater and may not be related to ammonia transformation. It should be noted that the qPCR method using circular plasmids employed in most of prior studies may lead to the overestimation of gene copy numbers. ${ }^{53}$

In addition to qPCR enumeration of amo $A$ genes, we employed 454-pyrosequencing and GeoChip to reveal the community, archaeal and amo $A$ gene diversities. The archaeal 454-pyrosequencing results revealed that the highest abundance of Thaumarcheota in archaeal population (99.60\%) occurred in the full-scale spiramycin system, followed by the pilot-scale spiramycin system ( $85.81 \%$ in average), with low abundance of Thaumarcheota found in the oxytetracycline (0.29\% in average), sewage $(0.02 \%$ in average), and inosine ( $0.03 \%$ in average) systems, which was in accordance with the qPCR results. Previously, archaeal 16S rRNA gene sequence analysis from marine and soil environments suggested that Thaumarchaeota can be divided into two distinct clades: group I.1a and group I.1b. ${ }^{11}$ Thaumarchaeota group I.1a is frequently found in marine environments, although it has been reported in terrestrial environments with low abundance. ${ }^{54}$ The Candidatus Nitrososphaera detected in our systems, which fell into group I.1b AOA, represented the most abundant soil taxa. ${ }^{54,55}$ This result was consistent with the findings of most earlier Arch-amoA gene sequences from WWTPs. ${ }^{11}$

Our GeoChip results revealed that the abundance of ArchamoA genes increased in the presence of spiramycin $(P<0.05)$. The VPA based on GeoChip analysis showed that antibiotics contributed the most to the $a m o A$ and $\mathrm{N}$-cycling functional gene variations ( 25.8 and $29.2 \%$, respectively), suggesting that antibiotics were the predominant factor shaping $\mathrm{N}$-cycling functional structures. The presence of relatively high spiramycin concentrations (especially in the spiramycin full-scale system) might have enhanced the role of Arch-amoA genes in ammonia 
removal by selecting for a greater abundance of archaeal species. Spiramycin is a macrolide antibiotic that inhibits the 50S ribosomal subunit, exhibiting activity against Gram-positive and some Gram-negative bacteria, ${ }^{56}$ and oxytetracycline inhibits the $30 \mathrm{~S}$ ribosomal subunit exhibiting activity against a wide range of Gram-positive and Gram-negative bacteria. ${ }^{57}$ In comparison with the classical bacteria, archaea have exhibited a different antimicrobial susceptibility pattern with respect to many basic biochemical characteristics. ${ }^{58,59}$ For example, human archaea could tolerate tetracycline and macrolide erythromycin at a concentration of $\geq 100 \mathrm{mg} / \mathrm{L} .{ }^{59}$ AOANitrososphaera viennensis was not affected by the antibiotics streptomycin, kanamycin, ampicillin, and carbenicillin. ${ }^{4}$ The half-maximal effective concentration of antibiotic sulfathiazole to AOB (Nitrosospira multiformis) was $7.70 \mu \mathrm{M}$, while that to AOA (ca. Nitrososphaera viennensis EN76) was over $1500 \mu \mathrm{M}^{60}$ Inhibitory effects of antibiotics on nitrification and AOB have been observed in wastewater treatment systems using shortterm inhibition tests or pilot experiments. ${ }^{22,23,61}$ The exposure of soil to certain antibiotics results a significant increase in the ratios of Arch-amoA to AOB amoA genes. ${ }^{62}$ Model calculations regarding the impact of antibiotics on $\mathrm{AOA}$ and $\mathrm{AOB}$ in soil ecosystems have shown that AOA maintained ammonia oxidation at high sulfadiazine concentrations. ${ }^{63,64}$ Thus, the sound nitrification in the two stably operated spiramycin wastewater treatment systems and the occurrence of abundant AOA in our study suggested that AOA might play an important role in nitrification. The relatively low AOA and Arch-amoA gene abundances in the oxytetracycline system might be related to the relatively low oxytretacycline concentrations or antibiotic type, which requires further study.

It should be also noted that the abundance of AOA over $\mathrm{AOB}$ in terms of $a m o A$ gene numbers might not necessarily be related to archaeal ammonia oxidation activity. Additional indepth analyses, including in situ labeling experiments, are needed to validate the role of AOA in wastewater treatment systems. At the same time, more samples from different WWTPs treating antibiotic production wastewater are needed to validate the result of this study.

\section{ASSOCIATED CONTENT}

\section{S Supporting Information}

Additional information as noted in text. The Supporting Information is available free of charge on the ACS Publications website at DOI: 10.1021/acs.est.5b01293.

\section{AUTHOR INFORMATION}

\section{Corresponding Authors}

*M. Yang. Phone: +86-10-62923475. Fax: +86-10-62923541. E-mail: yangmin@rcees.ac.cn.

*Y. Zhang. Phone: +86-10-62928390. Fax: +86-10-62923541. E-mail: zhangyu@rcees.ac.cn.

\section{Notes}

The authors declare no competing financial interest.

\section{ACKNOWLEDGMENTS}

This study was supported by National Natural Scientific Foundation of China (NSFC: 21437005; 51178449), State Hitech Research and Development Project of the Ministry of Science and Technology, Peoples Republic of China (Grand) (2012AA063401), special fund of State Key Joint Laboratory of Environmental Simulation and Pollution Control
(14103ESPC), and the Office of the Vice President for Research at the University of Oklahoma. We thank Dr. Huaqun Yin, Dr. Tong Zhang, Dr. Limei Zhang, and Dr. Ye Deng for their help in experiments, statistical analysis, and paper revising.

\section{REFERENCES}

(1) Venter, J. C.; Remington, K.; Heidelberg, J. F.; Halpern, A. L.; Rusch, D.; Eisen, J. A.; Wu, D.; Paulsen, I.; Nelson, K. E.; Nelson, W.; Fouts, D. E.; Levy, S.; Knap, A. H.; Lomas, M. W.; Nealson, K.; White, O.; Peterson, J.; Hoffman, J.; Parsons, R.; Baden-Tillson, H.; Pfannkoch, C.; Rogers, Y. H.; Smith, H. O. Environmental genome shotgun sequencing of the Sargasso Sea. Science 2004, 304 (5667), 66-74.

(2) Treusch, A. H.; Leininger, S.; Kletzin, A.; Schuster, S. C.; Klenk, H. P.; Schleper, C. Novel genes for nitrite reductase and Amo-related proteins indicate a role of uncultivated mesophilic crenarchaeota in nitrogen cycling. Environ. Microbiol. 2005, 7 (12), 1985-1995.

(3) Konneke, M.; Bernhard, A. E.; de la Torre, J. R.; Walker, C. B.; Waterbury, J. B.; Stahl, D. A. Isolation of an autotrophic ammoniaoxidizing marine archaeon. Nature 2005, 437 (7058), 543-546.

(4) Tourna, M.; Stieglmeier, M.; Spang, A.; Konneke, M.; Schintlmeister, A.; Urich, T.; Engel, M.; Schloter, M.; Wagner, M.; Richter, A.; Schleper, C. Nitrososphaera viennensis, an ammonia oxidizing archaeon from soil. Proc. Natl. Acad. Sci. U. S. A. 2011, 108 (20), 8420-8425.

(5) Koops, H.-P.; Pommerening-Roser, A.; Timmermann, G.; Wagner, M. The lithoautotrophic ammonia-oxidizing bacteria. In The Prokaryotes; Dworkin, M., F, S., Rosenberg, E, Dchleifer, K.-H., Stackebrandt, E., Eds.; Springer: New York, 2006.

(6) Prosser, J. I.; Nicol, G. W. Archaeal and bacterial ammoniaoxidisers in soil: the quest for niche specialisation and differentiation. Trends Microbiol. 2012, 20 (11), 523-531.

(7) Zhang, L. M.; Offre, P. R.; He, J. Z.; Verhamme, D. T.; Nicol, G. W.; Prosser, J. I. Autotrophic ammonia oxidation by soil thaumarchaea. Proc. Natl. Acad. Sci. U. S. A. 2010, 107 (40), 17240-17245.

(8) Zhang, L. M.; Hu, H. W.; Shen, J. P.; He, J. Z. Ammoniaoxidizing archaea have more important role than ammonia-oxidizing bacteria in ammonia oxidation of strongly acidic soils. ISME J. 2012, 6 (5), 1032-1045.

(9) Park, H. D.; Wells, G. F.; Bae, H.; Criddle, C. S.; Francis, C. A. Occurrence of ammonia-oxidizing archaea in wastewater treatment plant bioreactors. Appl. Environ. Microbiol. 2006, 72 (8), 5643-5647.

(10) You, J.; Das, A.; Dolan, E. M.; Hu, Z. Ammonia-oxidizing archaea involved in nitrogen removal. Water Res. 2009, 43 (7), 18011809.

(11) Limpiyakorn, T.; Furhacker, M.; Haberl, R.; Chodanon, T.; Srithep, P.; Sonthiphand, P. amoA-encoding archaea in wastewater treatment plants: a review. Appl. Microbiol. Biotechnol. 2013, 97 (4), 1425-1439.

(12) Wells, G. F.; Park, H. D.; Yeung, C. H.; Eggleston, B.; Francis, C. A.; Criddle, C. S. Ammonia-oxidizing communities in a highly aerated full-scale activated sludge bioreactor: betaproteobacterial dynamics and low relative abundance of Crenarchaea. Environ. Microbiol. 2009, 11 (9), 2310-2328.

(13) Zhang, T.; Jin, T.; Yan, Q.; Shao, M.; Wells, G.; Criddle, C.; HH, P. F. Occurrence of ammonia-oxidizing Archaea in activated sludges of a laboratory scale reactor and two wastewater treatment plants. J. Appl. Microbiol. 2009, 107 (3), 970-977.

(14) Yapsakli, K.; Aliyazicioglu, C.; Mertoglu, B. Identification and quantitative evaluation of nitrogen-converting organisms in a full-scale leachate treatment plant. J. Environ. Manage. 2011, 92 (3), 714-723.

(15) Sonthiphand, P.; Limpiyakorn, T. Change in ammonia-oxidizing microorganisms in enriched nitrifying activated sludge. Appl. Microbiol. Biotechnol. 2011, 89 (3), 843-853.

(16) Kayee, P.; Sonthiphand, P.; Rongsayamanont, C.; Limpiyakorn, T. Archaeal amoA Genes Outnumber Bacterial amoA Genes in 
Municipal Wastewater Treatment Plants in Bangkok. Microb. Ecol. 2011, 62 (4), 776-788.

(17) Limpiyakorn, T.; Sonthiphand, P.; Rongsayamanont, C.; Polprasert, C. Abundance of amoA genes of ammonia-oxidizing archaea and bacteria in activated sludge of full-scale wastewater treatment plants. Bioresour. Technol. 2011, 102 (4), 3694-3701.

(18) Mussmann, M.; Brito, I.; Pitcher, A.; Sinninghe Damste, J. S.; Hatzenpichler, R.; Richter, A.; Nielsen, J. L.; Nielsen, P. H.; Muller, A.; Daims, H.; Wagner, M.; Head, I. M. Thaumarchaeotes abundant in refinery nitrifying sludges express amoA but are not obligate autotrophic ammonia oxidizers. Proc. Natl. Acad. Sci. U. S. A. 2011, 108 (40), 16771-16776.

(19) Sauder, L. A.; Peterse, F.; Schouten, S.; Neufeld, J. D. Lowammonia niche of ammonia-oxidizing archaea in rotating biological contactors of a municipal wastewater treatment plant. Environ. Microbiol. 2012, 14 (9), 2589-2600.

(20) Larsson, D. G.; de Pedro, C.; Paxeus, N. Effluent from drug manufactures contains extremely high levels of pharmaceuticals. J. Hazard. Mater. 2007, 148 (3), 751-755.

(21) Li, D.; Yang, M.; Hu, J.; Ren, L.; Zhang, Y.; Li, K. Determination and fate of oxytetracycline and related compounds in oxytetracycline production wastewater and the receiving river. Environ. Toxicol. Chem. 2008, 27 (1), 80-86.

(22) Halling-Sørensen. Inhibition of Aerobic Growth and Nitrification of Bacteria in Sewage Sludge by Antibacterial Agents. Arch. Environ. Contam. Toxicol. 2001, 40 (4), 451-460.

(23) Gonzalez-Martinez, A.; Rodriguez-Sanchez, A.; MartinezToledo, M. V.; Garcia-Ruiz, M. J.; Hontoria, E.; Osorio-Robles, F.; Gonzalez-Lopez, J. Effect of ciprofloxacin antibiotic on the partialnitritation process and bacterial community structure of a submerged biofilter. Sci. Total Environ. 2014, 476-477, 276-287.

(24) Liu, M.; Ding, R.; Zhang, Y.; Gao, Y.; Tian, Z.; Zhang, T.; Yang, M. Abundance and distribution of Macrolide-Lincosamide-Streptogramin resistance genes in an anaerobic-aerobic system treating spiramycin production wastewater. Water Res. 2014, 63, 33-41.

(25) Zhang, Y.; Xie, J.; Liu, M.; Tian, Z.; He, Z.; van Nostrand, J. D.; Ren, L.; Zhou, J.; Yang, M. Microbial community functional structure in response to antibiotics in pharmaceutical wastewater treatment systems. Water Res. 2013, 47 (16), 6298-6308.

(26) Liu, J.; Yang, M.; Qi, R.; An, W.; Zhou, J. Comparative study of protozoan communities in full-scale MWTPS in Beijing related to treatment processes. Water Res. 2008, 42 (8-9), 1907-1918.

(27) Liu, M.; Zhang, Y.; Yang, M.; Tian, Z.; Ren, L.; Zhang, S. Abundance and distribution of tetracycline resistance genes and mobile elements in an oxytetracycline production wastewater treatment system. Environ. Sci. Technol. 2012, 46 (14), 7551-7557.

(28) Li, D.; Yang, M.; Hu, J.; Zhang, Y.; Chang, H.; Jin, F. Determination of penicillin $G$ and its degradation products in a penicillin production wastewater treatment plant and the receiving river. Water Res. 2008, 42 (1-2), 307-317.

(29) State Environmental Protection Administration of China. Standard Methods of Water and Wastewater Monitoring, 4th ed.; State Environmental Protection Administration of China: Beijing, China, 2002.

(30) Koike, S.; Krapac, I. G.; Oliver, H. D.; Yannarell, A. C.; CheeSanford, J. C.; Aminov, R. I.; Mackie, R. I. Monitoring and source tracking of tetracycline resistance genes in lagoons and groundwater adjacent to swine production facilities over a 3-year period. Appl. Environ. Microbiol. 2007, 73 (15), 4813-4823.

(31) Weiss, A.; Jerome, V.; Freitag, R.; Mayer, H. K. Diversity of the resident microbiota in a thermophilic municipal biogas plant. Appl. Microbiol. Biotechnol. 2008, 81 (1), 163-173.

(32) Francis, C. A.; Roberts, K. J.; Beman, J. M.; Santoro, A. E.; Oakley, B. B. Ubiquity and diversity of ammonia-oxidizing archaea in water columns and sediments of the ocean. Proc. Natl. Acad. Sci. U. S. A. 2005, 102 (41), 14683-14688.

(33) Rotthauwe, J. H.; Witzel, K. P.; Liesack, W. The ammonia monooxygenase structural gene amoA as a functional marker: molecular fine-scale analysis of natural ammonia-oxidizing populations. Appl. Environ. Microbiol. 1997, 63 (12), 4704-4712.

(34) Bustin, S. A.; Benes, V.; Garson, J. A.; Hellemans, J.; Huggett, J.; Kubista, M.; Mueller, R.; Nolan, T.; Pfaffl, M. W.; Shipley, G. L.; Vandesompele, J.; Wittwer, C. T. The MIQE Guidelines: Minimum Information for Publication of Quantitative Real-Time PCR Experiments. Clin. Chem. 2009, 55 (4), 611-622.

(35) Wu, S.; Wang, G.; Angert, E. R.; Wang, W.; Li, W.; Zou, H. Composition, diversity, and origin of the bacterial community in grass carp intestine. PLoS One 2012, 7 (2), e30440.

(36) Tian, Z.; Zhang, Y.; Li, Y.; Chi, Y.; Yang, M. Rapid establishment of thermophilic anaerobic microbial community during the one-step startup of thermophilic anaerobic digestion from a mesophilic digester. Water Res. 2015, 69, 9-19.

(37) Schloss, P. D.; Westcott, S. L.; Ryabin, T.; Hall, J. R.; Hartmann, M.; Hollister, E. B.; Lesniewski, R. A.; Oakley, B. B.; Parks, D. H.; Robinson, C. J.; Sahl, J. W.; Stres, B.; Thallinger, G. G.; Van Horn, D. J.; Weber, C. F. Introducing mothur: open-source, platformindependent, community-supported software for describing and comparing microbial communities. Appl. Environ. Microbiol. 2009, 75 (23), 7537-7541.

(38) Wang, Q.; Garrity, G. M.; Tiedje, J. M.; Cole, J. R. Naive Bayesian classifier for rapid assignment of rRNA sequences into the new bacterial taxonomy. Appl. Environ. Microbiol. 2007, 73 (16), 5261-5267.

(39) Ma, J.; Wang, Z.; Yang, Y.; Mei, X.; Wu, Z. Correlating microbial community structure and composition with aeration intensity in submerged membrane bioreactors by 454 high-throughput pyrosequencing. Water Res. 2013, 47 (2), 859-869.

(40) Magurran, A. E. Ecological Diversity and its Measurement; Princeton University Press: Princeton; New Jersey, 1988.

(41) Rosenzweig, M. L. Species Diversity in Space and Time; Cambridge University Press: New York, 1995.

(42) Zhou, J.; Bruns, M. A.; Tiedje, J. M. DNA recovery from soils of diverse composition. Appl. Environ. Microbiol. 1996, 62 (2), 316-322.

(43) Wang, C.; Wang, X.; Liu, D.; Wu, H.; Lu, X.; Fang, Y.; Cheng, W.; Luo, W.; Jiang, P.; Shi, J.; Yin, H.; Zhou, J.; Han, X.; Bai, E. Aridity threshold in controlling ecosystem nitrogen cycling in arid and semiarid grasslands. Nat. Commun. 2014, 5, 4799.

(44) Tu, Q. C.; Yu, H.; He, Z. L.; Deng, Y.; Wu, L. Y.; Van Nostrand, J. D.; Zhou, A. F.; Voordeckers, J.; Lee, Y. J.; Qin, Y. J.; Hemme, C. L.; Shi, Z.; Xue, K.; Yuan, T.; Wang, A. J.; Zhou, J. Z. GeoChip 4: a functional gene-array-based high-throughput environmental technology for microbial community analysis. Mol. Ecol. Resour. 2014, 14 (5), 914-928.

(45) Freeman, W. H. Biometry: the Principles and Practices of Statistics in Biological Research, third ed.; W. H. Freeman: New York, 1994.

(46) Mantel, N. The detection of disease clustering and a generalized regression approach. Cancer Res. 1967, 27, 209-220.

(47) Michael, I.; Rizzo, L.; McArdell, C. S.; Manaia, C. M.; Merlin, C.; Schwartz, T.; Dagot, C.; Fatta-Kassinos, D. Urban wastewater treatment plants as hotspots for the release of antibiotics in the environment: A review. Water Res. 2013, 47 (3), 957-995.

(48) Ma, W. L.; Qi, R.; Zhang, Y.; Wang, J.; Liang, C. Z.; Yang, M. Performance of a successive hydrolysis, denitrification and nitrification system for simultaneous removal of COD and nitrogen from terramycin production wastewater. Biochem. Eng. J. 2009, 45 (1), $30-34$.

(49) Jin, T.; Zhang, T.; Yan, Q. Characterization and quantification of ammonia-oxidizing archaea (AOA) and bacteria $(\mathrm{AOB})$ in a nitrogenremoving reactor using T-RFLP and qPCR. Appl. Microbiol. Biotechnol. 2010, 87 (3), 1167-1176.

(50) Peng, X.; Guo, F.; Ju, F.; Zhang, T. Shifts in the microbial community, nitrifiers and denitrifiers in the biofilm in a full-scale rotating biological contactor. Environ. Sci. Technol. 2014, 48 (14), 8044-8052.

(51) Erguder, T. H.; Boon, N.; Wittebolle, L.; Marzorati, M.; Verstraete, W. Environmental factors shaping the ecological niches of 
ammonia-oxidizing archaea. FEMS Microbiol. Rev. 2009, 33 (5), 855869.

(52) Li, H.; Mu, B. Z.; Jiang, Y.; Gu, J. D. Production Processes Affected Prokaryotic amoA Gene Abundance and Distribution in High-Temperature Petroleum Reservoirs. Geomicrobiol. J. 2011, 28 (8), 692-704.

(53) Hou, Y. B.; Zhang, H.; Miranda, L.; Lin, S. J. Serious Overestimation in Quantitative PCR by Circular (Supercoiled) Plasmid Standard: Microalgal pcna as the Model Gene. PLoS One 2010, 5 (3), 1-7.

(54) Hatzenpichler, R. Diversity, physiology, and niche differentiation of ammonia-oxidizing archaea. Appl. Environ. Microbiol. 2012, 78 (21), 7501-7510.

(55) Swanson, C. A.; Sliwinski, M. K. Archaeal assemblages inhabiting temperate mixed forest soil fluctuate in taxon composition and spatial distribution over time. Archaea 2013, 2013, 1-12.

(56) Mazzei, T.; Mini, E.; Novelli, A.; Periti, P. Chemistry and mode of action of macrolides. J. Antimicrob. Chemother. 1993, 31 (suppl C), $1-9$.

(57) Brodersen, D. E.; Clemons, J.; Carter, A. P.; Morgan-Warren, R. J.; Wimberly, B. T.; Ramakrishnan, V. The structural basis for the action of the antibiotics tetracycline, pactamycin, and hygromycin $b$ on the 30s ribosomal subunit. Cell 2000, 103 (7), 1143-1154.

(58) Hilpert, R. W. J.; Hammes, W.; Kandler, O. The sensitivity of archaebacteria to antibiotics. Zentralblatt für Bakteriologie Mikrobiologie und Hygiene: I. Abt. Originale C: Allgemeine. Zentralbl. Bakteriol., Mikrobiol. Hyg., Abt. 1, Orig. C 1981, 2 (1), 11-20.

(59) Khelaifia, S.; Drancourt, M. Susceptibility of archaea to antimicrobial agents: applications to clinical microbiology. Clin. Microbiol. Infect. 2012, 18 (9), 841-848.

(60) Shen, T.; Stieglmeier, M.; Dai, J.; Urich, T.; Schleper, C. Responses of the terrestrial ammonia-oxidizing archaeon Ca. Nitrososphaera viennensis and the ammonia-oxidizing bacterium Nitrosospira multiformis to nitrification inhibitors. FEMS Microbiol. Lett. 2013, 344 (2), 121-129.

(61) Louvet, J. N.; Giammarino, C.; Potier, O.; Pons, M. N. Adverse effects of erythromycin on the structure and chemistry of activated sludge. Environ. Pollut. 2010, 158 (3), 688-693.

(62) Magda, K. H. A. L. H.; Romain, M.; Edward, T. Multi-year and short-term responses of soil ammonia-oxidizing prokaryotes to zinc bacitracin, monensin, and ivermectin, singly or in combination. Environ. Toxicol. Chem. 2015, 34 (3), 618-625.

(63) Schauss, K.; Focks, A.; Heuer, H.; Kotzerke, A.; Schmitt, H.; Thiele-Bruhn, S.; Smalla, K.; Wilke, B.-M.; Matthies, M.; Amelung, W.; Klasmeier, J.; Schloter, M. Analysis, fate and effects of the antibiotic sulfadiazine in soil ecosystems. TrAC, Trends Anal. Chem. 2009, 28 (5), 612-618.

(64) Schauss, K.; Focks, A.; Leininger, S.; Kotzerke, A.; Heuer, H.; Thiele-Bruhn, S.; Sharma, S.; Wilke, B. M.; Matthies, M.; Smalla, K.; Munch, J. C.; Amelung, W.; Kaupenjohann, M.; Schloter, M.; Schleper, C. Dynamics and functional relevance of ammonia-oxidizing archaea in two agricultural soils. Environ. Microbiol. 2009, 11 (2), 446-456. 